\title{
Genetic and phenotypic parameters for productive traits in the first three lactations of Khuzestan buffaloes in Iran
}

\author{
Mostafa Madad, Navid Ghavi Hossein-Zadeh and Abdol Ahad Shadparvar \\ Department of Animal Science, Faculty of Agricultural Sciences, University of Guilan, Rasht, Iran
}

\begin{abstract}
The objective of this study was to estimate genetic parameters for milk and fat yields in Khuzestan buffaloes of Iran. A total of 5258 production records of the first three lactations of the Khuzestan buffaloes obtained from the Animal Breeding Centre of Iran between 1993 and 2009 were used for the analysis. Genetic parameters were estimated by the multivariate restricted maximum-likelihood (REML) procedure in the Wombat program. The averages of milk and fat production were $2220.0 \mathrm{~kg}$ and $137.6 \mathrm{~kg}$ for first lactation; $2236.8 \mathrm{~kg}$ and $137.9 \mathrm{~kg}$ for second lactation; and $2303.6 \mathrm{~kg}$ and $143.3 \mathrm{~kg}$ for third lactation, respectively. Heritability estimates for milk and fat yields were 0.06 and 0.24 for the first; 0.06 and 0.28 for the second and 0.26 and 0.47 for the third lactation, respectively. Genetic correlation estimates between first and second, first and third, and second and third lactations were $0.77,0.67$ and 0.79 for milk and $-0.61,-0.21$ and -0.25 for fat yields. These estimates for milk yield are consistent with previous estimates obtained from animal models. Milk production of different lactations is essentially the same trait genetically and combining all lactation records as a single trait is appropriate. On the other hand, negative genetic correlations for fat yield in different lactations indicated that fat yields in all lactations were determined by different genes.
\end{abstract}

Keywords: genetic parameters; heritability; genetic correlation; milking buffaloes 


\section{Introduction}

Buffaloes of Iran can be grouped in three main classes based on climate conditions: 1) Azari ecotype (Western and Eastern Azerbaijan), 2) North ecotype (Guilan and Mazendaran), 3) Khuzestan ecotype (Khuzestan). Iranian water buffaloes have also similarities to Iraqi buffaloes (Tavakolian 2000). There are about 480000 water buffaloes in Iran. Most of these animals are maintained in the south and northwest. All of the Iranian buffaloes are riverine (Naserian \& Saremi 2007). Buffaloes are multi-purpose and most valuable livestock species in smallholder mixed farming system in some parts of Iran. Khuzestan, a province in the southwest of Iran, is one of the important regions for raising buffaloes. More than $22 \%$ of the buffalo population in Iran is found in this area with a herd size of 5 to 300 animals (Naderfard \& Qanemy 1997). The world buffalo milk production intensified $43 \%$ from 1997 to 2007. This rate is greater than that reported for cow milk production (20\%) in the same period (FAO 2009). However, buffalo milk yield is still much lower than cow's milk yield. In 2007, worldwide buffalo and cow milk productions were 85 and 560 million tonnes, respectively (FAO 2009). In the last decades, the Brazilian buffalo milk yield per lactation has significantly increased from $717.3 \mathrm{~kg}$ in 1995 (Tonhati et al. 1996) to $1650.0 \mathrm{~kg}$ in recent years (Ramos et al. 2006, Tonhati et al. 2008). This is mainly a consequence of the improvement in management, infrastructure and feeding practices on buffalo farms (Malhado et al. 2007). However, to develop a buffalo breeding program it is necessary to implement systematic milk recording to collect phenotypic and pedigree data (Seno et al. 2007). Buffalo milk is characterised by a high percentage of fat and protein, which could be used to increase milk's added value, following the current tendency of the worldwide milk markets. In the process of cheese making, fat and casein are the major milk solids incorporated into the final product; thus, these milk components are routinely used in many countries as a criterion to determine the milk price. Dairy sire evaluations mainly use first lactation records or repeated records assuming correlation of unity among yields in different lactations. These two procedures assume that first lactation yields can provide adequate information about later lactation yields, implying that the same genes influence first and later lactation yields. The main benefit obtained by using later lactations for sire evaluation is the increased accuracy of evaluation that occurs mainly due to the increase in the number of ties among sires (Meyer 1983). There is a reasonable agreement to include later lactations in dairy cattle evaluation (Cassell \& McDaniel 1983, Meyer 1983). Multipletrait analysis, considering different lactation yields as different traits, would be more demanding in computational time but could take into account differences in variances, fixed effects, and possible bias in later lactations from selection in early lactations. Thus, objectives of this study were to estimate genetic and phenotypic (co)variances among lactations separately for milk and fat yields using an animal model to determine whether yields in different lactations can be considered to be one trait.

\section{Material and methods}

The data consisted of 5258 records of cows of 240 days, twice daily milking, mature equivalent yields for milk and fat in the first, second and third lactations of Khuzestan buffaloes calving from 1993 to 2009. Records for the first three lactations of Khuzestan buffaloes were obtained from the Animal Breeding Centre of Iran. Buffalo cows were mated naturally. Yields for the first, second, and third lactations were considered as different traits. Using the general linear 
model (GLM) procedure in SAS v9.1 software (SAS Institute, Cary, NC, USA), fixed factors that are registered for productive traits were identified as herd, year and season of calving. The summary of the edited data and production averages for the first three lactations of Khuzestan buffaloes is shown in Table 1.

Table 1

Summary of data and production averages and their standard deviations for the first three lactations of Khuzestan buffaloes

\begin{tabular}{lccr}
\hline Item & first & \multicolumn{2}{c}{$\begin{array}{c}\text { Lactation } \\
\text { second }\end{array}$} \\
\hline No. of sires with progeny & $53(48)$ & $114(111)$ & third \\
No. of records & $1658(1575)$ & $1976(1945)$ & $113(111)$ \\
No. of herds & $268(259)$ & $292(284)$ & $1624(1594)$ \\
No. of year-seasons & $58(57)$ & $58(58)$ & $291(288)$ \\
Production averages & & & $54(54)$ \\
Milk yield, kg & $2220.03 \pm 548.9$ & $2236.8 \pm 531.4$ & $2303.6 \pm 549.6$ \\
Fat yield, kg & $137.6 \pm 42.4$ & $137.9 \pm 43.2$ & $143.3 \pm 43.3$ \\
\hline
\end{tabular}

*Numbers in parentheses are records with fat test.

The following animal model in the matrix form was used for the analyses:

$$
y=X \beta+Z a+e
$$

where $y$ is a vector of milk or fat yields in each of the first three lactations, $\beta$ is a vector of fixed effects (herd, year-season of calving), $\boldsymbol{a}$ is a vector of additive genetic values of animals, $\boldsymbol{e}$ is a vector of residual effects, $X$ and $Z$ are incidence matrices for fixed and random effects. Assumptions of the model were as follows:

$$
\begin{aligned}
& V(a)=G=A \sigma_{a}^{2} \\
& V(e)=R=I \sigma_{e}^{2} \\
& \operatorname{Cov}(a, e)=0
\end{aligned}
$$

Multivariate animal models were used to estimate genetic and phenotypic correlations between first-, second- and third-lactation milk or fat yield separately. The models applied in multivariate analyses were the same as those fitted for the genetic analysis of each trait in the univariate analyses and were, in matrix notation, as follows:

$$
\left[\begin{array}{l}
y_{1} \\
y_{2} \\
y_{3}
\end{array}\right]=\left[\begin{array}{lll}
x_{1} & 0 & 0 \\
0 & x_{2} & 0 \\
0 & 0 & x_{3}
\end{array}\right]\left[\begin{array}{l}
b_{1} \\
b_{2} \\
b_{3}
\end{array}\right]+\left[\begin{array}{lll}
z_{1} & 0 & 0 \\
0 & z_{2} & 0 \\
0 & 0 & z_{3}
\end{array}\right]\left[\begin{array}{l}
u_{1} \\
u_{2} \\
u_{3}
\end{array}\right]+\left[\begin{array}{l}
e_{1} \\
e_{2} \\
e_{3}
\end{array}\right]
$$

where $y_{1}, y_{2}$ and $y_{3}$ are the vectors of observations for milk or fat yields in different lactations; $b_{1}, b_{2}$ and $b_{3}$ denoted the fixed effects in the models with association matrices $X_{1}, X_{2}$ and $X_{3}$; $u_{1}, u_{2}$ and $u_{3}$ are the vectors of direct genetic effects with the incidence matrices $Z_{1}, Z_{2}$ and $Z_{3^{\prime}}$; and $e_{1}, e_{2}$ and $e_{3}$ denoted the vectors of residual effects. The (co)variance components needed to estimate the genetic parameters for the traits under study were obtained by restricted maximum-likelihood (REML) method of the Wombat program (Meyer 2007). 


\section{Results and discussion}

Estimates of genetic, environmental and phenotypic (co)variances for the yields of milk and fat in the first, second and third lactations are presented in Table 2 . For milk yield, a reduction in the additive genetic variance was observed from the first to the second lactation and an increase was observed in the third compared to the first two. Environmental variance remained the same for the first and second lactations and showed a small decrease with advancing lactations, although the reduced number of observations during the third lactation did not permit definitive conclusions about the values obtained. The genetic components for fat yield increased with the lactation number, whereas the environmental components remained constant. Thus, the heritabilities increased with the lactation number. Beaumont (1989) obtained similar results for milk yield but genetic components for the contents measured showed different trends in dairy cattle.

Table 2

Estimates of genetic (g), environmental (e) and phenotypic (p) variances $\left(\sigma^{2}\right)$ and covariances $(\sigma)$ for yields of milk and fat in the first (1), second (2) and third (3) lactations

\begin{tabular}{lcc}
\hline Item & Milk yield & Fat yield \\
\hline$\sigma_{\mathrm{g} 1}^{2}$ & 8112.7 & 194.1 \\
$\sigma_{\mathrm{g} 2}^{2}$ & 7695.7 & 240.2 \\
$\sigma_{\mathrm{g} 3}^{2}$ & 36810 & 421.5 \\
$\sigma_{\mathrm{e} 1}^{2}$ & 119580 & 593.9 \\
$\sigma_{\mathrm{e} 2}^{2}$ & 119490 & 592.1 \\
$\sigma_{\mathrm{e} 3}^{2}$ & 101770 & 467.9 \\
$\sigma_{\mathrm{g} 1,2}^{2}$ & 6115.3 & -133.3 \\
$\sigma_{\mathrm{g} 1,3}$ & 11618 & -60 \\
$\sigma_{\mathrm{g} 2,3}$ & 13382 & -79.5 \\
$\sigma_{\mathrm{e} 1,2}$ & 19771 & 200.5 \\
$\sigma_{\mathrm{e} 1,3}$ & -7317.1 & 34.1 \\
$\sigma_{\mathrm{e} 2,3}$ & 203 \\
$\sigma_{\mathrm{p} 1,2}$ & 24966 & 67.2 \\
$\sigma_{\mathrm{p} 1,3}$ & 25887 & -25.8 \\
$\sigma_{\mathrm{p} 2,3}$ & 4300.8 & 123.4 \\
\hline
\end{tabular}

Heritability estimates were obtained by multivariate analysis for the first three lactations for milk and fat yields. Heritability estimates were $0.06,0.06$ and 0.26 for milk yield and were $0.24,0.28$ and 0.47 for fat yield in the first three parities, respectively (Table 3 ). It is indicated that estimates remained the same from the first to the second lactation and then increased from the second to the third. The only exception was for fat yield, where the heritability estimate for the second lactation was equal to 0.28 and slightly higher than the estimate for the first lactation (0.24). Maijala \& Hanna (1974) in dairy cattle have surveyed the literature and reported weighted average heritabilities for the first three lactations of $0.26,0.20$ and 0.17 for milk yield and $0.25,0.16$ and 0.17 for fat yield. Meyer (1984), who studied the same traits in specialised dairy breeds, obtained heritabilities for lactations 1 to 3 of $0.28,0.19$ and 0.24 for milk yield and $0.27,0.21$ and 0.25 for fat yield. Estimates of heritabilities for milk yield were lower in the first and second lactations and were greater in the third lactation. The estimate of heritability for first lactation fat yield in this study agreed with the abovementioned results 
but heritability estimates for the second and third lactations were greater in the current study. Heritability estimate for the first lactation milk yield was lower than the estimate obtained by Tonhati et al. (2000), Rosati \& Van Vleck (2002) and Aspilcueta-Borquis et al. (2010) in milking buffaloes, suggesting that milk yield has enough additive genetic variation to respond to selection. According to Aspilcueta-Borquis et al. (2010), there are many aspects that influenced the values obtained. There is a big variability within and across herds which makes the phenotypic and environmental variances become bigger. There are also mistakes in the paternal identification of the animals and this makes a genetic variability loss. Heritabilities for fat yield are higher, especially for the second and third lactations than those commonly reported, which may be due to using an animal model that may be less affected by selection than sire models. Aspilcueta-Borquis et al. (2010) obtained a heritability estimate for the first lactation fat yield of 0.21 . Rosati \& Van Vleck (2002), working with Italian buffaloes and applying the restricted maximum-likelihood (REML) method, reported about lower heritability estimates (0.11) for this trait. Differences in environmental conditions and management between Brazil and Italy and Iran may explain the difference between results from the three countries. Zinvand et al. (2010) reported the heritability estimate was 0.07 for milk yield in Khuzestan buffaloes. In the other study on the same breed, heritability estimates of milk and fat yields were 0.077 and 0.056 , respectively (Morammazi et al. 2007). Also, Nazari et al. (2010) obtained heritability estimates of milk and fat yields in Khuzestan buffaloes of 0.22 and 0.18 , respectively.

Table 3

Estimates of heritabilities $\left(\mathrm{h}^{2}\right)$ and genetic $(\mathrm{g})$, environmental (e) and phenotypic (p) correlations ( $\mathrm{r}$ ) for milk and fat yields in the first (1), second (2) and third (3) lactations

\begin{tabular}{llc}
\hline Item & Milk yield & Fat yield \\
\hline$h_{1}{ }^{2}$ & $0.06 \pm 0.03$ & $0.24 \pm 0.24$ \\
$h_{2}^{2}$ & $0.06 \pm 0.03$ & $0.28 \pm 0.17$ \\
$h_{3}^{2}$ & $0.26 \pm 0.01$ & $0.47 \pm 0.24$ \\
$r_{g 1,2}$ & 0.77 & -0.61 \\
$r_{g 1,3}$ & 0.67 & -0.21 \\
$r_{g 2,3}$ & 0.79 & -0.25 \\
$r_{e 1,2}$ & 0.16 & 0.33 \\
$r_{e 1,3}$ & -0.06 & 0.06 \\
$r_{e 2,3}$ & 0.22 & 0.38 \\
$r_{p 1,2}$ & 0.20 & 0.08 \\
$r_{p 1,3}$ & 0.03 & -0.03 \\
$r_{p 2,3}$ & 0.28 & 0.14 \\
\hline
\end{tabular}

Genetic correlations for milk yield calculated by multivariate analysis were 0.77 between the first and second lactation, 0.67 between the first and third and 0.79 between the second and third (Table 3). These genetic correlations were between -0.21 and -0.61 for fat yields in different lactations. Meyer (1984) reported about genetic correlations of 0.91, 0.91 and 0.95 for milk yield and 0.91, 0.91 and 0.99 for fat yield in dairy cattle, between lactations 1 and 2, 1 and 3, and 2 and 3, respectively. Visscher et al. (1992) reported about high genetic correlation estimates for yield traits in dairy cattle. The correlation between the first and third lactations was smaller than the others. The same trend was observed for the environmental 
and phenotypic correlations: the correlations between adjacent lactations (between first and second lactations or second and third lactations) were higher than those between the first and third lactations. Genetic correlations for milk yield in our study were greater than 0.60. The high genetic correlation between milk yield traits reported in this study implies that genes that positively influence milk yield in one parity would result in greater values of milk yield in other parities. The high and positive genetic correlations between milk yield traits are an evidence for a common genetic and physiological mechanism controlling these traits. Also, a positive and high genetic correlation between the milk traits suggesting that selection of dairy cows in favour of milk yield in a parity would also improve other milk traits. Negative correlations between fat yields in this study were unexpected. Therefore, fat yields in different lactations were not statistically the same traits. Phenotypic correlations for milk yield and fat yield were between 0.03 to 0.28 and -0.03 to 0.14 , respectively. These estimates were lower than the estimates reported by Visscher et al. (1992), Swalve \& Van Vleck (1987) for milk and fat yields in dairy cattle. Treating different lactations as the same trait genetically is justified.

In conclusion, heritability estimates for the first three lactation yields of milk and fat are lower for first lactation and higher for subsequent lactations. Genetic variances were not the same for the first three lactations. Genetic correlations for milk yield in different lactations were consistently high and close to unity; indicating that milk yields in all lactations were determined to a large extent by the same genes. Negative correlations between fat traits indicated a weak relationship between different lactations.

\section{References}

Aspilcueta-Borquis RR, Araujo Neto FR, Baldi F, Bignardi AB, Albuquerque LG, Tonhati H (2010) Genetic parameters for buffalo milk yield and milk quality traits using Bayesian inference. J Dairy Sci 93, 2195-2201

Beaumont C (1989) Restricted maximum likelihood estimation of genetic parameters for the first three lactations in the Montbéliarde dairy cattle breed. Genet Sel Evol 21, 493-506

Cassell BG, McDaniel BT (1983) Use of Later Records in Dairy Sire Evaluation: A Review. J Dairy Sci 66, 1-10

FAO (2009) http://faostat.fao.org. [last accessed 24.02.2013]

Maijala K, Hanna M (1974) Reliable phenotypic and genetic parameters in dairy cattle. In: Proc 1st World Congr Genet Appl Livest Prod 1, 541-563

Malhado CHM, Ramos AA, Carneiro PLS, de Souza JC, Piccinin A (2007) [Genetic and phenotypic parameters for milk production of Murrah buffaloes]. R Bras Zootec 36, 376-379 [in Portuguese]

Meyer K (1983) Scope for evaluating dairy sires using first and second lactation records. Livest Prod Sci 10, 531-553

Meyer K (1984) Estimates of genetic parameters for milk and fat yield for the first three lactations in British Friesian cows. Anim Prod 38, 313-322

Meyer, K (2007) WOMBAT - A tool for mixed model analyses in quantitative genetics by REML. J Zhejiang Uni Science B 8: 815-821

Morammazi S, Vaez Torshizi R, Rouzbehan Y, Sayyadnejad MB (2007) Estimates of genetic parameters for production and reproduction traits in Khuzestan buffalos of Iran. Ital J Anim Sci 6, (Suppl.), 421-424

Naderfard HR, Qanemy AW (1997) Buffalo breeding in Islamic Republic of Iran. In: Proceedings of the 5th World Buffalo Congress, Caserta, Italy, 942-943

Naserian AA, Saremi B (2007) Water buffalo industry in Iran. Ital J Anim Sci 6 (Suppl.), 1404-1405 
Nazari M, Fayazi J, Tabatabaei S, Aghaei A, Mamoei M (2010) Investigation of the Genetic and Phenotypic Potential of Productive Traits Using the Uni and Multiple Traits Animal Model in River Buffalo. J Anim Vet Adv 9, 1479-1481

Ramos AA, Malhado CHM, Carneiro PLS, Gonçalves HC, Azevedo DMMR (2006) [Phenotypic and genetic characterization of the milk yield and calving interval in buffalo of the Murrah breed]. Pesq Agropec Bras 41, 1261-1267 [in Portuguese]

Rosati A, Van Vleck LD (2002) Estimation of genetic parameters for milk, fat, protein and mozzarella cheese production for the Italian river buffalo Bubalus bubalis population. Livest Prod Sci 74, 185-190

SAS (2002) User's Guide: Statistics, Version 9.1 Edition. SAS Institute Inc., Cary, NC, USA

Seno LO, Cardoso VL, Tonhati H (2007) [Economic values for milk production traits of dairy buffaloes in São Paulo State]. R Bras Zootec 36 (Suppl.), 2016-2022 [in Portuguese]

Swalve H, Van Vleck LD (1987) Estimation of Genetic (Co)Variances for Milk Yield in First Three Lactations Using an Animal Model and Restricted Maximum Likelihood. J Dairy Sci 70, 842-849

Tavakolian J (2000) [An introduction to genetic resources of native farm animals]. Animal Science Research Institute, Karaj, Iran [in Persian]

Tonhati H, Cerón-Muñoz MF, de Oliveira JA, El Faro L, Lima ALF, de Albuquerque LG (2008) Test-day milk yield as a selection criterion for dairy buffaloes (Bubalus bubalis Artiodactyla, Bovidae). Genet Mol Biol 31, 674-679

Tonhati H, Vasconcellos FB, Albuquerque LG (2000) Genetic aspects of productive and reproductive traits in a Murrah buffalo herd in São Paulo, Brazil. J Anim Breed Genet 117, 331-336

Tonhati H, Baruselli PS, Oliveira JFS, Vasconcellos BF, Toledo LM (1996) Calving season, peak of lactation and milk production of the buffalo in Ribeira Valley, São Paulo State Brazil. Rev Bubalus Bubalis, Salerno, Italia, 3, 63-67

Visscher PM, Hill WG, Thompson R (1992) Univariate and multivariate parameter estimates for milk production traits using an animal model. II. Efficiency of selection when using simplified covariance structures. Genet Sel Evol 24, 431-447

Zinvand B, Farhangfar H, Emamjome Kashan N, Jafari Khorshidi K (2010) Estimation of environmental and genetic effects for production traits at buffaloes in Khuzestan province. In: Proceeding of the 4th Congress on Animal Science, September, Tehran University, Tehran-Karaj, Iran, 2780-2783 